\title{
THE MARKETING-ENTREPRENEURSHIP PARADOX: A FREQUENCY-DOMAIN ANALYSIS
}

\section{Slavka T. Nikolić, Nikola Gradojević, Vladimir Đaković, Valentina Mladenović, Jelena Stanković}

\section{Introduction}

The notion of entrepreneurship is not new, but entrepreneurship is continuously searching for new ideas while increasing their applications (Morris \& Trotter, 1990; Morris, Lewis, \& Sexton, 1994). Marketing and entrepreneurship are broadening their field of synergic activity, but some gaps in this interaction still remain (Bhuian, Menguc, \& Bell, 2005). Numerous studies have indicated the link between marketing and entrepreneurship (Murray, 1981; Morris \& Paul, 1987; Herron, Sapienza, \& Smith-Cook, 1992; Hills \& LaForge, 1992; Becherer \& Maurer, 1998; Morris, Schindehutte \& LaForge, 2002; Kraus, Harms, \& Fink, 2010; Gilmore, 2011, Hills \& Hultman, 2011; Hultman \& Hills 2011; Kurgun, Bagiran, Ozeren, \& Maral, 2011; Morrish, 2011; Busenitz, Plummer, Klotz, Shahzad, \& Rhoads, 2014), but a number of research question have remained underexplored.

This paper addresses the relative scarcity of scholarly work that directly tests the causality in the frequency domain between the entrepreneurial activities and marketing in the function of gaining and maintaining distinctive market advantage of a company. Hence, the focus of this research is on a company's profitability with special attention on organizational changes and the measure of acceptable risk in marketing.

Nowadays business environment is abundant in uncertainty, volatility and compromises, and for such a reason risk emerges as a major factor in management (Alvarez \& Barney, 2005; Cramer, Hartog, Jonker, \& Van Praag, 2002), whereas entrepreneurship efforts become basic prerequisites of success (Morris, Schindehutte, \& LaForge, 2002). This implies that in order to accept the changes and grow entrepreneurship must not only have dynamic abilities (Menguc, \& Bell, 2005), but also an innovative character
(Stokes, 2000). Essentially, entrepreneurship always includes risk that may range from low to high levels (Morris, Schindehutte, \& LaForge, 2002). This paper contributes to the study of Davis, Morris, and Allen (1991) on the management capacity for exposure to risk by taking into account that entrepreneurial activities entail a threat of very expensive failure. Specifically, the contribution of this paper lies in combining marketing with entrepreneurial activities in order to manage organizational changes aimed at assessing the measure of acceptable risk and profitability in the long run. Scholarly contributions of many authors (Morris \& Trotter, 1990; Miller, 1983; Morris, Davis, \& Ewing, 1988; Knight, 2000; Bhuian, Menguc, \& Bell, 2005; Naldi, Nordqvist, Sjöberg, \& Wiklund, 2007) define entrepreneurship as a process whose main characteristics are innovativeness, proactivity and ability to take business risk, thereby making the link between entrepreneurship and marketing even stronger. Our research motivation is concentrated on examining the integral interplay between these two disciplines. Certain particularities of this phenomenon can be observed from the company size, but the analysis presented in this paper differs from other studies because it clarifies the complementarity of the mutual influence of entrepreneurial and marketing activities. Our findings complement and expand the literature on the relationship between entrepreneurship and marketing by depicting that synergy through the multi-scale (i.e., frequency-dependent) cycle or the so-called "spiral of success".

The main goal of this paper is to test and analyze the causality-driven relationship between entrepreneurship and marketing, i.e., the marketing-entrepreneurship paradox, with the particular attention on the company's marketing decisions in regards to profitability. We advocate 
the view that marketing and entrepreneurship operations are inseparable activities, from which a word "marketpreneurship" can be derived. Based on the theoretical concepts and methodology of causality in the frequency domain (Gradojevic \& Lento, 2015; Gradojevic \& Dobardzic, 2013) supported by the case study, we design our proposed research framework and draw our conclusions from the data, as well as from the graphical representation of the "spiral of success". Our results show that changes in marketing expense are able to predict changes in net income at both medium and long horizons (at business cycle frequencies of 3-7 years). In the context of our "spiral of success", we show that the companies may not only be successful in facing high risk when the organizational changes were intense (in the short to medium run), but also when the organizational changes were not intense (in the long run).

We also point to the paradox in risky market conditions, where the measure of adequacy of organizational response will determine the measure of business success. More specifically, we emphasize the existence of the marketingentrepreneurship paradox caused by risk, organizational changes and the level of product diversification. This research is significant both to the academic and professional communities with particular importance for the optimal business decision-making processes, while contributing and expanding the current literature in the field of marketing-entrepreneurship. To the authors' best knowledge, this paper is the first to perform the causality tests in the frequency domain for the bivariate system that contains changes in net income and marketing expense.

In the next section, we present the theoretical concepts and in Section 2 we specify our proposed research framework. Section 3 describes our research methodology for working in the frequency domain, while Section 4 presents the data characteristics. In Section 5 , we present the results and discuss them in the context of our theoretical conjectures. The final section concludes the paper.

\section{Theoretical Background}

Considering the proximity of entrepreneurship and marketing as scientific disciplines, it is surprising that relatively little "cross-fertilization" has occurred (Herron, Sapienza, \& SmithCook, 1992, p. 6). During the 1980's, it was suggested that management explorers should be encouraged to make an effort to identify whether entrepreneurship and marketing interdepend and in which way (Morris \& Paul, 1987). Almost a decade and a half later, after numerous researches of many authors, some of them who were optimistic (e.g., Hultman \& Hills, 2011) claimed that the relationship between entrepreneurship and marketing should still be examined, while others (e.g., Miles, Crispin, \& Kasouf, 2011) pointed out that it is difficult to define the entrepreneurship-marketing link. There exist significant areas of overlap between the marketing discipline and the study of entrepreneurship, and managers should be prepared to "borrow boldly" from marketing in order to advance the theory of entrepreneurship (Hills \& LaForge, 1992).

It is worthwhile to note that the synergy between entrepreneurship and marketing is so strong that many authors integrate these terms in different ways, among which the one used most often is entrepreneurial marketing (Kraus, Harms, \& Fink, 2010; Lagrosen \& Svensson, 2006; Hills \& Hultman, 2011; Morris, Schindehutte, \& LaForge, 2002; Kurgun, Bagiran, Ozeren, \& Maral, 2011; Morrish, 2011; Gilmore, 2011). This approach, however, has a potential drawback in the fact that the majority of these researchers have considered that entrepreneurship is related to small or middle-sized enterprises (Knight, 2000; Jones \& Rowley, 2011; Kurgun, Bagiran, Ozeren, \& Maral, 2011; Fairlie \& Holleran, 2012; António \& Mendes, 2013), while identifying the entrepreneurship with the entrepreneur, i.e., the owner of such an enterprise. Nevertheless, many papers have introduced the argument that entrepreneurial orientation can be embedded in large companies as well as in small and middlesized companies (Morris \& Paul, 1987; Davis, Morris, \& Allen, 1991; Miles \& Darroch, 2006; Lagrosen \& Svensson, 2006; Kraus, Harms, \& Fink, 2010). Some authors such as Morris \& Trotter (1990) and Sebora \& Theerapatvong (2010) go even further by using the phrase corporative entrepreneurship in the context of the ability to stimulate the attributes of small entrepreneurial companies in larger and more developed companies (Kuratko, Hornsby, Naffziger, \& Montagno, 1993), and, more generally, understanding it as a comprehensive effort of an organization to spread internally (Morris, Lewis, \& Sexton, 1994). 
The present world of consumption is characterized by the syndrome of instantism and this phenomenon is governed by speed, anxiety and volatility. This in turn reinforces the notion of innovativeness that is necessary for market entry (Nikolic, Tumbas, Kostres, \& Stankovic, 2013). We view innovativeness from the company perspective (Danneels \& Kleinschmidt, 2001) as a creative process of making new products, techniques or technologies (Knight, 2000) and as a starting point for the organizational innovativeness (Amabile, Conti, Coon, Lazenby, \& Herron, 1996). Consequently, innovativeness is the key mechanism for the organizational growth and it has a central significance in the efforts of achieving competitiveness (Lawson \& Samson, 2001). Moreover, new marketing trends offer an opportunity for increasing marketing influence on enterprise competitiveness (Pilik, 2008).

It is important to note that innovation generates changes and growth; that is why entrepreneurship involves a form of "continuous crisis". Kotler, Wong, Saunders and Armstrong (2004) argued that day-to-day activities of economic agents are marked by uncertainty, discontinuity, disturbance and threat. Through organizational innovativeness, entrepreneurship tracks the frequency of changes, it increases the business risk, but it also potentially improves the profitability of an organization (Morris, Schindehutte, \& LaForge, 2002). Marketing, on the other hand, by the means of communication both internally and externally in an organization, represents the process of working on differences that strengthens the market position and represents a control mechanism for finding the true measure of innovativeness. Hence, the contemporaneous orientation of a company towards entrepreneurship and marketing represents a novel paradigm that guides a company to its optimal business performance (Atuahene-Gima \& Ko, 2001). The combination of these two orientations also represents a strategic response to the turbulent environment that companies frequently face (Morris \& Paul, 1987; Bhuian, Menguc, \& Bell, 2005; AtuaheneGima \& Ko, 2001). The key ingredient for the symbiosis between entrepreneurship and marketing is innovation (Davis, Morris, \& Allen, 1991; Lagrosen \& Svensson, 2006).

It can be argued that marketing is uniquely capabletoanalyzethe(r)evolution inthebusiness environment and anticipate new possibilities for entrepreneurial activities (e.g., Pilik, 2008; Busenitz, Plummer, Klotz, Shahzad, \& Rhoads, 2014). Moreover, marketing shelters the entrepreneurial process and provides it with directions for future business expansion (Murray, 1981). Also, marketing is in charge of interaction with the business environment (Davis, Morris, \& Allen, 1991). Nonetheless, one should not only focus on the global view of marketing, but also on its temporal dynamics, by which marketing pushes an organization along the "spiral of success". Essentially, it is necessary to understand the business cycle patterns of the activities that lead to business success or failure (Newman, 2007). "The rapid pace of change means that the firm's ability to change will become a competitive advantage" (Kotler, Wong, Saunders \& Armstrong, 2004). This means that a company must try to harmonize its entrepreneurial orientation with the market response (Atuahene-Gima \& Ko, 2001). It becomes an imperative to manage a business system through the cycles of new developmental undertakings, by moving along the "spiral of success" and avoiding the path of organizational failure.

\section{The Paradox of Marketing- Entrepreneurship: "Spiral of Success"}

Our model is based on the premise that being aware of the change is necessary for business development, where entrepreneurship manages the development, while marketing manages risk. In other words, marketing determines the level of acceptable risk which facilitates climbing the spiral of organizational success. Marketing as an organizational function is significantly affected by the degree of entrepreneurial orientation of a company (Kraus, Harms, \& Fink, 2010). However, the long-term outlook of the entrepreneurial orientation is determined by the quality of marketing activities (Kotler, Wong, Saunders, \& Armstrong, 2004). More importantly, it should be stressed that markets that are constantly changing are not a threat, but initiators of marketing (Busenitz, Plummer, Klotz, Shahzad, \& Rhoads, 2014). Such markets create opportunities that are not common to the periods of market stability.

The "spiral of success" of an organization that shows a dynamic link between entrepreneurship and marketing involves two parameters that define its temporal characteristics (Fig. 1). 


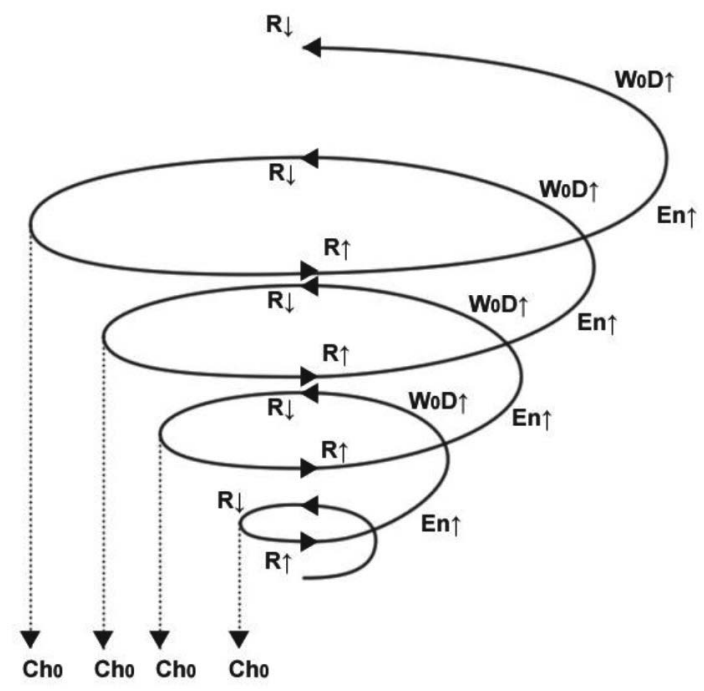

Source: own

The diameter of the spiral defines a measure of diversification, while the step of the spiral represents a measure of frequency or instances when an organization enters new developmental cycles. The "spiral of success" of a welldeveloped organization is characterized by shorter step sizes and a wider diameter, which can be interpreted as frequent developmental cycles with higher level of diversification (i.e., new fields of business operations). To survive in a competitive environment, high frequency and diversity are a necessity.

In particular, an increase in changes, as the basis of entrepreneurial activities (En $\nearrow$ ) leads to an increase in risk $(\mathrm{R} \nearrow$ ) that a business faces. The increase in risk demands strong marketing activities that should resolve the problem by working on differences (WoD), i.e., by creating a competitive advantage that causes a decrease in the risk $(R \downarrow)$ and increase in the dynamic stability of the system. But, in the longrun, the lack of organizational changes $\left(\mathrm{Ch}_{0}\right)$ may lead to an increase in risk (R $\lambda$ ) because it may decrease the competitive advantage of the organization and thereby strengthen its market competition. We emphasize the paradox: when the organizational changes are intense, but also when they are not, the organization faces high risk (Morris, Schindehutte, \& LaForge, 2002). Such adverse developments require entry in a new cycle of entrepreneurial activities by the way of innovation that not only increases risk $(\mathrm{R} \nearrow)$, but also creates a market advantage from another WoD cycle.

In general, marketing and entrepreneurship are directly related to the firm's profitability (Becherer \& Maurer, 1998). A successful development of new products and services is able to sustain growth and maintain profitability of healthy companies in the long run (Kotler, Wong, Saunders, \& Armstrong, 2004). This means that marketing performs the role of a conduit that provides an entrepreneurial momentum (Morris \& Paul, 1987). Taken jointly, entrepreneurship and marketing offer a possibility to develop unique solutions tailored to meet the requirements of buyers in the socalled marketpreneurship-oriented businesses (McAuley, 2011).

\section{Methodology: Causality in the Frequency Domain}

The test for causality in the frequency domain by Breitung and Candelon (2006) originates 
from Geweke (1982) and Hosoya (1991). Let $z_{t}=\left[x_{t}, y_{t}\right]^{\prime}$ be a two-dimensional time series vector with $t=1, \ldots, T$. It is assumed that $z_{t}$ has a finite-order VAR representation

$$
\Theta(L) z_{t}=\varepsilon_{t}
$$

where $\Theta(L)=I-\Theta_{1} L-\ldots-\Theta_{p} L^{p}$ is a $2 \times 2$ lag polynomial with $L^{k} z_{t}=z_{t-k^{*}}$. It is assumed that the vector $\varepsilon_{t}$ is white noise with $E\left(\varepsilon_{t}\right)=0$ and $E\left(\varepsilon_{t} \varepsilon_{t}^{\prime}\right)=\Sigma$, where $\Sigma$ is a positive definite matrix. Next, let $G$ be the lower triangular matrix of the Cholesky decomposition $G^{\prime} G=\Sigma^{-1}$, such that $E\left(\eta_{t} \eta_{t}{ }^{\prime}\right)=I$ and $\eta_{t}=G \varepsilon_{t^{\prime}}$. The system is assumed to be stationary, implying the following MA representation:

$$
\begin{aligned}
z_{t} & =\Phi(L) \varepsilon_{t}=\left[\begin{array}{ll}
\Phi_{11}(L) & \Phi_{12}(L) \\
\Phi_{21}(L) & \Phi_{22}(L)
\end{array}\right]\left[\begin{array}{l}
\varepsilon_{1 t} \\
\varepsilon_{2 t}
\end{array}\right] \\
& =\Psi(L) \eta_{t}=\left[\begin{array}{ll}
\Psi_{11}(L) & \Psi_{12}(L) \\
\Psi_{21}(L) & \Psi_{22}(L)
\end{array}\right]\left[\begin{array}{l}
\eta_{1 t} \\
\eta_{2 t}
\end{array}\right]
\end{aligned}
$$

where $\Phi(L)=\Theta(L)^{-1}$ and $\Psi(L)=\Phi(L)^{-1} G^{-1}$. Using this representation, the spectral density of $x_{t}$ can be expressed as

$$
f_{x}(\omega)=\frac{1}{2 \pi}\left\{\left|\Psi_{11}\left(e^{-i \omega}\right)\right|^{2}+\left|\Psi_{12}\left(e^{-i \omega}\right)\right|^{2}\right\}
$$

The measure of causality suggested by Geweke (1982) and Hosoya (1991) is defined as

$$
\begin{aligned}
& M_{y \rightarrow x}(\omega)=\log \frac{2 \pi f_{x}(\omega)}{\left|\Psi_{11}\left(e^{-i \omega}\right)\right|^{2}} \\
& =\log \left[1+\frac{\left|\Psi_{12}\left(e^{-i \omega}\right)\right|^{2}}{\left|\Psi_{11}\left(e^{-i \omega}\right)\right|^{2}}\right]
\end{aligned}
$$

This measure is zero if $\left|\Psi_{12}\left(e^{-i \omega}\right)\right|=0$ in which case it is said that $y$ does not cause $x$ at frequency $\omega$. To test the hypothesis that $y$ does not cause $x$ at frequency $\omega$ the following null hypothesis is used:

$$
M_{y \rightarrow x}(\omega)=0
$$

Yao and Hosoya (2000) estimate $M_{y \rightarrow x}(\omega)=0$ by replacing $\left|\Psi_{11}\left(e^{-i \omega}\right)\right|$ and $\left|\Psi_{12}\left(e^{-i \omega}\right)\right|$ from Equation (5) with estimates obtained from the fitted VAR. However, this approach is not appropriate since $\left|\Psi_{12}\left(e^{-i \omega}\right)\right|$ is a complicated nonlinear function of the VAR parameters. Yao and Hosoya (2000) propose a numerical estimation procedure instead of an exact analytical expression. Breitung and Candelon (2006) resolve this problem by showing that the null hypothesis $M_{y \rightarrow x}(\omega)=0$ is equivalent to a linear restriction on the VAR coefficients. First, they use $\Psi(L)=\Theta(L)^{-1} G^{-1}$ and $\Psi_{12}(L)=-\frac{g^{22} \Theta_{12}(L)}{|\Theta(L)|}$ (where $g^{22}$ is the lower diagonal element of $G^{-1}$ and $|\Theta(L)|$ is the determinant of $\Theta(L))$ to express the null hypothesis as

$$
\begin{aligned}
& \left|\Theta_{12}\left(e^{-i \omega}\right)\right|=\mid \sum_{k=1}^{p} \theta_{12, k} \cos (k \omega)- \\
& -\sum_{k=1}^{p} \theta_{12, k} \sin (k \omega) i \mid=0,
\end{aligned}
$$

where $\theta_{12, k}$ is the $(1,2)$-element of $\Theta_{k}$. Thus, a necessary and sufficient set of conditions for

$$
\begin{gathered}
\left|\Theta_{12}\left(e^{-i \omega}\right)\right|=0 \text { is } \\
\sum_{k=1}^{p} \theta_{12, k} \cos (k \omega)=0, \\
\sum_{k=1}^{p} \theta_{12, k} \sin (k \omega)=0,
\end{gathered}
$$

The notation can be simplified by letting $a_{j}=\theta_{11, j}$ and $\beta_{j}=\theta_{12, j^{\prime}}$. Then, the VAR equation for $x_{t}$ can be written as

$$
\begin{aligned}
& x_{t}=a_{1} x_{t-1}+\ldots+a_{p} x_{t-p}+ \\
& +\beta_{1} y_{t-1}+\ldots+\beta_{p} y_{t-p}+\varepsilon_{1 t} .
\end{aligned}
$$

The hypothesis $M_{y \rightarrow x}(\omega)=0$ is equivalent to the linear restriction

$$
H_{0}: R(\omega) \beta=0,
$$


where $\beta=\left[\beta_{1}, \ldots, \beta_{p}\right]^{\prime}$ and

$$
R(\omega)=\left[\begin{array}{llll}
\cos (\omega) & \cos (2 \omega) & \ldots & \cos (p \omega) \\
\sin (\omega) & \sin (2 \omega) & \ldots & \sin (p \omega)
\end{array}\right]
$$

The ordinary $F$ statistic for (11) is approximately distributed as $F(2, T-2 p)$ for $\omega \in(0, \pi)$. As in Breitung and Candelon (2006), to assess the statistical significance of the causal relationship between exchange rate returns and order flows, the causality measure for $\omega \in(0, \pi)$ is compared to the $5 \%$ critical value of a $X^{2}$-distribution with 2 degrees of freedom (5.99). Breitung and Candelon (2006) study the local power of the test when the frequency being tested converges to the true frequency and show that the Wald statistic is asymptotically distributed as non-central $X^{2}$.

\section{Data Description}

The data set is for Amazon.com (AMZN), sampled at a quarterly frequency and was obtained from Bloomberg. The date for the IPO of AMZN was May 14, 1997. Thus, the data for net income (NI) and marketing expense (MKT) span the period between
June 30, 1997 and November 30, 2014, for the total of 70 observations. The units for both variables are millions of U.S. dollars (USD). As Fig. 2 indicates, the MKT variable is potentially non-stationary and trending, while such data features are not obvious for net income that exhibits occasional volatility outbursts.

Tab. 1 presents the summary statistics for MKT and NI. On average, $\mathrm{NI}$ is lower than MKT and this confirms AMZN's commitment to large marketing budget. Standard deviations for both variables are larger than the means, thus, indicating highly volatile and overdispersed variables. With respect to skewness, $\mathrm{NI}$ is roughly normally distributed and MKT is positively skewed. This is in line with the observed data features in Fig. 2. Finally, both series display excess kurtosis which emphasizes large tail risk.

$\mathrm{NI}$ and MKT are considered in first-difference terms in order to avoid theoretical problems of inference with non-stationary variables. To support this claim, standard Dickey-Fuller and Phillips-Perron unit roots tests are performed on both variables (Tab. 2). MKT is found to be integrated of order one and $\mathrm{NI}$ is borderline stationary at the $5 \%$ significance level. When

\section{Fig. 2: Net income and marketing cost for Amazon.com [AMZN]}

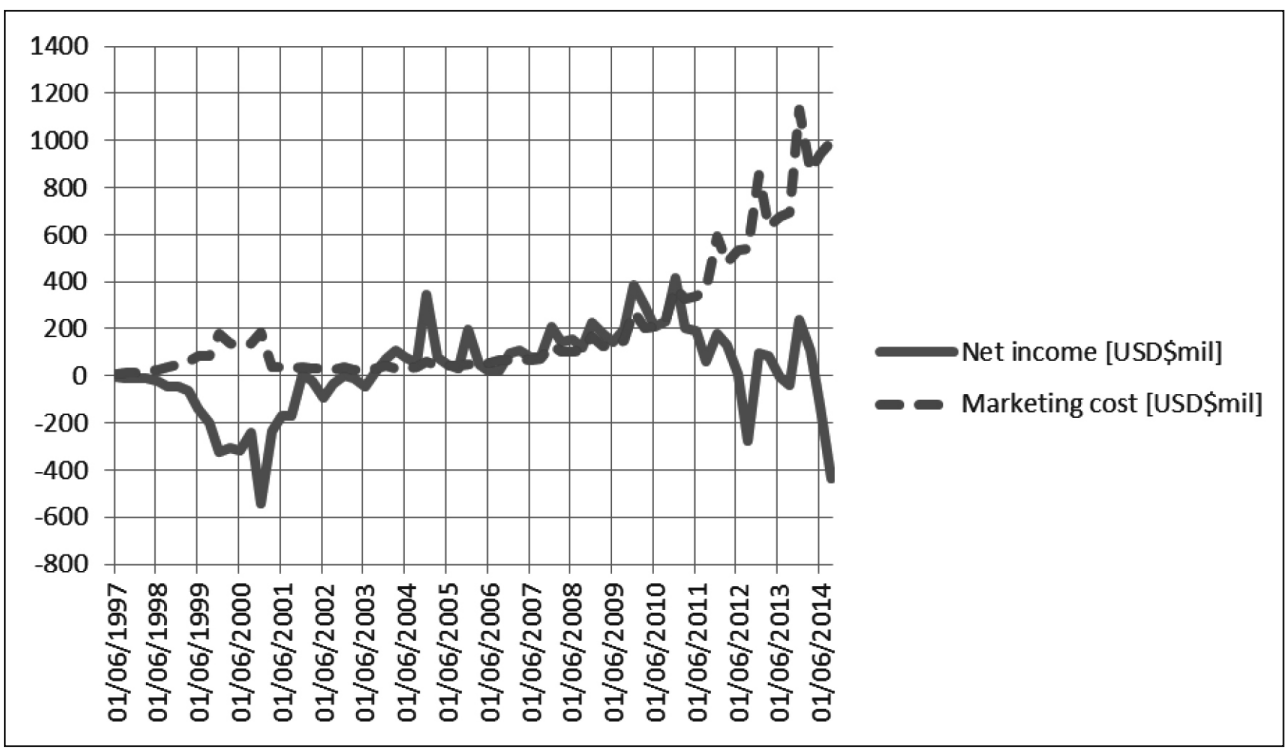




Tab. 1: Summary statistics
\begin{tabular}{l|c|c|c|c|c|c|c|c} 
& & & & & \\
Variable & Obs & Mean & Std. Dev. & Min & Max & Median & Skewness & Kurtosis \\
\hline NI & 70 & 25.13 & 181.94 & -545.14 & 416 & 40.50 & -0.64 & 3.84 \\
\hline MKT & 70 & 209.32 & 272.63 & 7.77 & 1,133 & 79.97 & 1.78 & 5.25 \\
\hline
\end{tabular}

\section{Tab. 2: Non-stationarity tests}

\begin{tabular}{l|c|c|c}
\multicolumn{1}{c|}{ Variable } & PP p-value & ADF p-value & Lags \\
\hline $\mathrm{NI}$ & 0.035 & 0.051 & 13 \\
\hline MKT & 0.997 & 0.998 & 5 \\
\hline Change in NI & 0.000 & 0.000 & 1 \\
\hline Change in MKT & 0.000 & 0.006 & 9 \\
\hline \multicolumn{4}{r}{}
\end{tabular}

\section{Fig. 3: Causality tests for $\Delta M K T$ and $\Delta$ NI for Amazon.com}

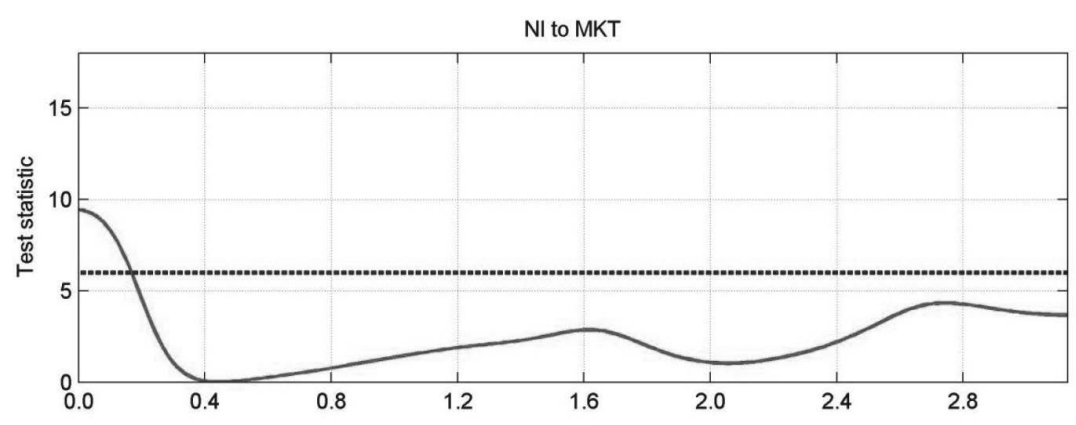

$\omega$

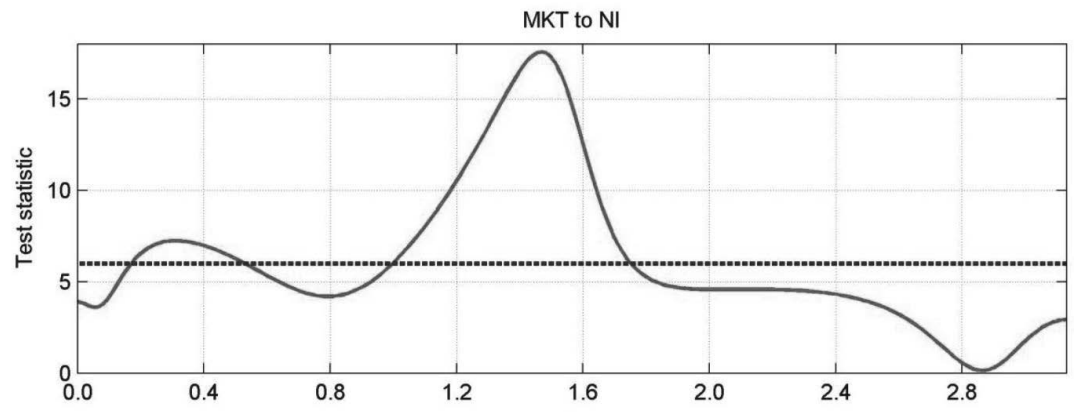

Source: own 
the variables were transformed to their quarterly changes, the null hypothesis of non-stationarity is rejected at the $99 \%$ significance level.

\section{Results}

This section reports the results of causality tests in the frequency domain for the bivariate system that contains change in MKT ( $\triangle \mathrm{MKT}$ ) and change in $\mathrm{NI}(\Delta \mathrm{NI})$. Both Dickey Fuller and Phillips-Perron tests reject the null hypothesis of a unit root in the $\Delta \mathrm{MKT}$ and $\Delta \mathrm{NI}$ time series at the $1 \%$ significance level. According to the AIC criterion, a VAR(8) model was selected for both systems.

Fig. 3 presents the causality measure between $\triangle \mathrm{MKT}$ and $\Delta \mathrm{NI}$ for all frequencies $(\omega \in(0, \pi))$ along with the $5 \%$ critical value (5.99) that is represented with a horizontal dashed line. The top panel indicates that the null hypothesis of no causality from $\Delta \mathrm{NI}$ to $\triangle \mathrm{MKT}$ is rejected when $\omega<0.20$ which corresponds to very low frequencies with a wavelength of roughly $7-8$ years (31 quarters $=2 \pi / \omega)$. Hence, it takes a long period of time before any changes in $\mathrm{NI}$ impact changes in MKT. These findings show to a certain extent an independence of marketing decisions relative to the profitability of the company.

The bottom panel of Fig. 3 reveals evidence of causality from $\Delta \mathrm{MKT}$ to $\Delta \mathrm{NI}$ in the medium run for $\omega \in[1,1.7]$ (between 3.69 and 6.28 quarters, i.e., the lag length is between one and one and a half years) and long run $\omega \in[0.2,0.5]$ (i.e., 3-7 years). These findings demonstrate that changes in MKT are able to predict changes in $\mathrm{NI}$ at both medium and long horizons. In other words, marketing expense is an important determinant of profitability with a dual impact, one that results in the short to medium run response of $\Delta \mathrm{NI}$ (1-1.5 year-lag) and the other that drives profitability at business cycle frequencies (3-7 years).

In the context of our "spiral of success" depicted in Fig. 1, we show that AMZN has not only been successful in facing high risk when the organizational changes were intense (in the short to medium run), but also when the organizational changes were not intense (in the long run). Specifically, AMZN was able to enter new cycles of entrepreneurial activities and marketing, and create a distinctive market advantage that resulted in their profitability. More broadly, as the company has been constantly innovating and diversifying over the sample years, AMZN has validated our premise that a successful company needs to enter more frequent developmental cycles with a greater level of diversification.

\section{Conclusions}

A large body of research suggests that entrepreneurially-oriented businesses need marketing and that entrepreneurial activities are necessary for marketing-oriented businesses. The interaction between the two disciplines is thus a potentially rich research area. The goal of this paper is to lay out multidisciplinary foundations for the formal theoretical and practical treatment of this important research question. On the theoretical side, we stress that the interaction between marketing and entrepreneurship leads to a paradoxical situation: when organizational changes are intense and also when they are not, an organization faces high risk. Such developments necessitate a new cycle of entrepreneurial (i.e., innovation) activities that will result in even more risk, but they will cause a switch to a new developmental cycle, until the innovativeness of entrepreneurial organization and/or its marketing create a cycle of distinctive market advantage. With this article, we emphasize the complex relationship between marketing, entrepreneurship and finance that is frequency-dependent and follows certain periodicity. We develop a theoretical model and test its validity on market data.

On the empirical side, we study the interaction of marketing, profitability and entrepreneurial activities in the frequency domain for the information obtained from the financial statements of Amazon.com, Inc. We document that marketing efforts are able to predict changes in net income at both medium and long horizons. In particular, Amazon. com, Inc. was able to enter new cycles of entrepreneurial activities and marketing create a distinctive market advantage that resulted in their profitability.

Nevertheless, in the most recent years (2014 and 2015), the profitability of Amazon has become more variable. The unprecedented negative net income was recorded in 2014 (-241 USD\$mil), but the company's innovative business model prevailed in 2015 and generated a strong positive net income of 328 USD\$mil. Meanwhile, the market showed a strong support for the company 
and, consequently, the stock price followed an upward trend over the years, until the end of 2015. Our model suggests that the observed success originated in the frequency of new developmental cycles. Indeed, a variety of Amazon's innovations and new services such as Fire TV, Dash, Travel, Echo, Alexa and PrimeAir (drone delivery) emerged in 2014 and 2015. This recent evidence and our empirical findings support our theoretical conjecture that a successful company needs to enter more frequent developmental cycles with a greater level of diversification. Our future research efforts will focus on conceptualizing a dynamic model for a panel of companies that have been successfully diversifying their business model.

The authors would like to thank the Editor and the two anonymous referees for their helpful comments and suggestions.

\section{References}

Alvarez, S. A., \& Barney, J. B. (2005). How Do Entrepreneurs Organize Firms Under Conditions of Uncertainty? Journal of Management, 31(5), 776-793. doi: 10.1177/0149206305279486

Amabile, T. M., Conti, R., Coon, H., Lazenby, J., \& Herron, M. (1996). Assessing the Work Environment for Creativity. Academy of Management Journal, 39(5), 1154-1184. doi:10.2307/256995.

Atuahene-Gima, K., \& Ko, A. (2001). An Empirical Investigation of the Effect of Market Orientation and Entrepreneurship Orientation Alignment on Product Innovation. Organization science, 12(1), 54-74. doi:10.1287/ orsc.12.1.54.10121.

Becherer, R. C., \& Maurer, J. G. (1998). The Moderating Effect of Environmental Variables on the Entrepreneurial and Marketing Orientation of Entrepreneur-led Firms. Entrepreneurship Theory and Practice, 22(1), 47-58.

Berlin, I. (1958). Two Concepts of Liberty. In I. Berlin (Ed.), Four Essays on Liberty (1969). Oxford: Oxford University Press.

Bhuian, S. N., Menguc, B., \& Bell, S. J. (2005). Just Entrepreneurial Enough: The Moderating Effect of Entrepreneurship on the Relationship Between Market Orientation and Performance. Journal of Business Research, 58(1), 9-17. doi:10.1016/S0148-2963(03)00074-2.

Breitung, J., \& Candelon, B. (2006). Testing for short- and long-run causality: A frequency-domain approach. Journal of Econometrics, 132(2), 363-378. doi:10.1016/j.jeconom.2005.02.004.

Busenitz, L. W., Plummer, L. A., Klotz, A. C., Shahzad, A., \& Rhoads, K. (2014). Entrepreneurship Research (1985-2009) and the Emergence of Opportunities. Entrepreneurship Theory and Practice, 38(5), 981-1000. doi:10.1111/etap.12120.

Cramer, J. S., Hartog, J., Jonker, N., \& Van Praag, C. M. (2002). Low Risk Aversion Encourages the Choice for Entrepreneurship: An Empirical Test of a Truism. Journal of Economic Behavior \& Organization, 48(1), 2936. doi:10.1016/S0167-2681(01)00222-0.

Danneels, E., \& Kleinschmidt, E. J. (2001). Product Innovativeness from the Firm's Perspective: Its Dimensions and Their Relation with Project Selection and Performance. Journal of Product Innovation Management, 18(6), 357-373. doi:10.1016/S0737-6782(01)00109-6.

Davis, D., Morris, M., \& Allen, J. (1991). Perceived Environmental Turbulence and Its Effect on Selected Entrepreneurship, Marketing, and Organizational Characteristics in Industrial Firms. Journal of the Academy of Marketing Science, 19(1), 43-51. doi:10.1007/BF02723423.

Geweke, J. (1982). Measurement of linear dependence and feedback between multiple time series. Journal of the American Statistical Association, 77(378), 304-324. doi:10.2307/2287238.

Gilmore, A. (2011). Entrepreneurial and SME marketing. Journal of Research in Marketing and Entrepreneurship, 13(2), 137-145. doi:10.1108/14715201111176426.

Gradojevic, N., \& Lento, C. (2015). Multiscale analysis of foreign exchange order flows and technical trading profitability. Economic Modelling, 47, 156-165. doi:10.1016/j.econmod.2015.02.028.

Gradojevic, N., \& Dobardzic, E. (2013). Causality between regional stock markets: Afrequency domain approach. Panoeconomicus, 60(5), 633-647. doi:10.2298/PAN1305633G.

Herron, L., Sapienza, H. J., \& Smith-Cook, D. (1992). Entrepreneurship Theory from an Interdisciplinary Perspective: Volume II. Entrepreneurship Theory and Practice, 16(3), 5-11.

Hills, G. E., \& Hultman, C. M. (2011). Academic Roots: The Past and Present of Entrepreneurial Marketing. Journal of Small Business \& Entrepreneurship, 24(1), 1-10. doi:10.1080/08276331.2011.10593521. 
Hills, G. E., \& LaForge, R. W. (1992). Research at the Marketing Interface to Advance Entrepreneurship Theory. Entrepreneurship Theory and Practice, 16(3), 33-59.

Hosoya, Y. (1991). The decomposition and measurement of the interdependence between second-order stationary process. Probability Theory and Related Fields, 88(4), 429-444. doi:10.1007/BF01192551.

Hultman, C. M., \& Hills, G. E. (2011). Influence from Entrepreneurship in Marketing Theory. Journal of Research in Marketing and Entrepreneurship, 13(2), 120-125. doi:10.1108/14715201111176408.

Jones, R., \& Rowley, J. (2011). Entrepreneurial Marketing in Small Businesses: A Conceptual Exploration. International Small Business Journal, 29(1), 25-36. doi:10.1177/0266242610369743.

Knight, G. (2000). Entrepreneurship and marketing strategy: The SME under globalization. Journal of International Marketing, 8(2), 12-32. doi:10.1509/jimk.8.2.12.19620.

Kotler, P., Wong, V., Saunders, J., \& Armstrong, G. (2004). Principles of Marketing (4th European ed.). Harlow: Prentice Hall.

Kraus, S., Harms, R., \& Fink, M. (2010). Entrepreneurial Marketing: Moving Beyond Marketing in New Ventures. International Journal of Entrepreneurship and Innovation Management, 11(1), 19-34. doi:10.1504/IJEIM.2010.029766.

Kuratko, D. F., Hornsby, J. S., Naffziger, D. W., \& Montagno, R. V. (1993). Implement Entrepreneurial Thinking in Established Organizations. SAM Advanced Management Journal, 58(1), 28-39.

Kurgun, H., Bagiran, D., Ozeren, E., \& Maral, B. (2011). Entrepreneurial Marketing - The Interface Between Marketing and Entrepreneurship: A qualitative Research on Boutique Hotels. European Journal of Social Sciences, 26(3), 340-357.

Lagrosen, S., \& Svensson, G. (2006). Marketing - Broadening the Horizons (Eds.). Studentlitteratur.

Lawson, B., \& Samson, D. (2001). Developing Innovation Capability in Organisations: A Dynamic Capabilities Approach. International Journal of Innovation Management, 5(3), 377-400. doi:10.1142/S1363919601000427.

McAuley, A. (2011). Lost or Just at a Crossroads: Is Entrepreneurship the Way Forward for Marketing? Journal of Research in Marketing and Entrepreneurship, 13(2), 161-166. doi:10.1108/14715201111176444.

Mendes, L. A. F. (2013). Senior Managers and SMEs' Propensity to Quality Improvement Programs - A Comparative Analysis. E\&M Ekonomie a Management, 16(4), 89-103.

Miles, M. P., \& Darroch, J. (2006). Large Firms, Entrepreneurial Marketing Processes, and the Cycle of Competitive Advantage. European JournalofMarketing, 40(5/6), 485-501. doi:10.1108/03090560610657804.

Miles, M. P., Crispin, S., \& Kasouf, C. J. (2011). Entrepreneurship's Relevance to Marketing. Journal of Research in Marketing and Entrepreneurship, 13(2), 126-136. doi:10.1108/14715201111176417.

Miller, D. (1983). The Correlates of Entrepreneurship in Three Types of Firms. Management Science, 29(7), 770-791.

Morris, M. H., \& Paul, G. W. (1987). The Relationship between Entrepreneurship and Marketing in Established Firms. Journal of Business Venturing, 2(3), 247-259. doi:10.1016/0883-9026(87)90012-7.

Morris, M. H., \& Trotter, J. D. (1990). Institutionalizing Entrepreneurship in a Large Company: A Case Study at AT\&T. Industrial Marketing Management, 19(2), 131-139. doi:10.1016/0019-8501(90)90037-V.

Morris, M. H., Davis, D. L., \& Ewing, J. (1988). The Role of Entrepreneurship in Industrial Marketing Activities. Industrial Marketing Management, 17(4), 337-346. doi:10.1016/0019-8501(88)90037-5.

Morris, M. H., Lewis, P. S., \& Sexton, D. L. (1994). Reconceptualizing Entrepreneurship: An Input-Output Perspective. SAM Advanced Management Journal, 59(1), 21-31.

Morris, M. H., Schindehutte, M., \& LaForge, R. W. (2002). Entrepreneurial Marketing: A Construct for Integrating Emerging Entrepreneurship and Marketing Perspectives. Journal of Marketing Theory and Practice, 10(4), 1-19. doi:10.1080/10696679.2002.11501922.

Morrish, S. C. (2011). Entrepreneurial Marketing: A Strategy for the Twenty-first Century? Journal of Research in Marketing and Entrepreneurship, 13(2), 110-119. doi:10.1108/14715201111176390.

Murray, J. A. (1981). Marketing is Home for the Entrepreneurial Process. Industrial Marketing Management, 10(2), 93-99. doi:10.1016/0019-8501(81)90002-X. 
Naldi, L., Nordqvist, M., Sjöberg, K., \& Wiklund, J. (2007). Entrepreneurial Orientation, Risk Taking, and Performance in Family Firms. Family Business Review, 20(1), 33-47. doi:10.1111/j.1741-6248.2007.00082.x.

Newman, A. F. (2007). Risk-Bearing and Entrepreneurship. Journal of Economic Theory, 137(1), 11-26. doi:10.1016/j.jet.2007.03.004.

Nikolic, S., Tumbas, P., Kostres, M., \& Stankovic, J. (2013). The New Marketing Management Approach: The Glocal Prosumer. In H.-J. Bullinger, \& D. Spath (Eds.), Engineering Management - Challenges for the Future (pp. 103-126). Novi Sad, Serbia: Faculty of Technical Sciences, Stuttgart, Germany: Fraunhofer IAO, Vienna, Austria: DAAAM International.

Pilik, M. (2008). Nové marketingové trendy jako príležitost zvýšení vlivu marketingu na dosažení konkurenčních výhod. E\&M Ekonomie a Management, 11(2), 107-119.

Sebora, T. C., \& Theerapatvong, T. (2010). Corporate Entrepreneurship: A Test of External and Internal Influences on Managers' Idea Generation, Risk Taking, and Proactiveness. International Entrepreneurship and Management Journal, 6(3), 331-350. doi:10.1007/s11365-009-0108-5.

Stokes, D. (2000). Putting Entrepreneurship into Marketing: The Processes of Entrepreneurial Marketing. Journal of Research in Marketing and Entrepreneurship, 2(1), 1-16. doi:10.1108/14715200080001536.

Yao, F., \& Hosoya, Y. (2000). Inference on one-way effect and evidence in Japanese macroeconomic data. Journal of Econometrics, 98(2), 225-255. doi:10.1016/S0304-4076(99)00084-6.
Assoc. Prof. Slavka T. Nikolić, Ph.D.

University of Novi Sad

Faculty of Technical Sciences

Department for Industrial Engineering and Management snikolic@uns.ac.rs

Assoc. Prof. Nikola Gradojević, Ph.D. University of Guelph

Department of Economics and Finance College of Business and Economics and

University of Novi Sad Faculty of Technical Sciences Department for Industrial Engineering and Management ngradoje@uoguelph.ca

Assist. Prof. Vladimir Đaković, Ph.D. University of Novi Sad Faculty of Technical Sciences Department for Industrial Engineering and Management v_djakovic@uns.ac.rs

Valentina Mladenović, MSc Polytehnic - School of New Technologies v.mladenovic@uns.ac.rs

Jelena Stanković, MSc University of Novi Sad

Faculty of Technical Sciences Department for Industrial Engineering and Management stankovicj@uns.ac.rs 


\section{Abstract}

\section{THE MARKETING-ENTREPRENEURSHIP PARADOX: A FREQUENCY-DOMAIN ANALYSIS}

\section{Slavka T. Nikolić, Nikola Gradojević, Vladimir Đaković, Valentina Mladenović, Jelena Stanković}

The areas of overlap between the disciplines of marketing and entrepreneurship are substantial and they provide a wide variety of opportunities for multidisciplinary research. This paper lays out multidisciplinary foundations for the formal theoretical and practical treatment of the interaction between marketing, entrepreneurship and profitability in an organization. The focus of this research is on a company's success as a function of organizational changes and the level of acceptable risk, measured by its profitability. The contribution to the literature on the relationship between entrepreneurship and marketing is reflected in a new approach that relies on the multi-scale (i.e., frequency-dependent) approach or the so-called "spiral of success". In addition, this paper highlights the necessity for dynamic abilities and innovative character in an organization. More broadly, it explains an important theoretical paradox that organizations always face high risk, but, in order to survive in business, they need to enter new cycles of entrepreneurial activities (innovation and diversification) that involve even more risk. The novelty of this study lies in its application of the causality tests in the frequency domain for the bivariate system in order to demonstrate the marketing-entrepreneurship paradox. This is, to the authors' best knowledge, the first paper that uses such a methodology in marketing and entrepreneurship. The paper's principal hypothesis is tested on a well-diversified company (Amazon.com) where it is shown that marketing drives changes in net income at both medium and long horizons, but not vice-versa. The findings and related discussions can be useful to academics and practitioners, as well as to public policy-makers.

Key Words: Marketing, entrepreneurship, causality, frequency-domain, innovation.

JEL Classification: M31, L26, C22.

DOI: 10.15240/tul/001/2017-3-014 